\title{
Opportunities and Obstacles of a Healthy Diet from an Economic and Psychological Aspect
}

\author{
Nikolett Mihály \\ University of Szent István, Institute of Business Sciences, Hungary \\ Nándor Komáromi \\ University of Szent István, Institute of Business Sciences, Hungary \\ József Lehota \\ University of Szent István, Institute of Business Sciences, Hungary
}

\section{Abstract}

The issue of healthy consumption is an extremely timely topic in today's fast-paced world. One of today's ruling trends is health consciousness and the expansion of the health market. The role of health for consumers has been appreciated. People spend more and more to preserve their health. The consequence of conscious consumption is that individuals can keep their physical and mental health for a longer time and can remain active, and accordingly, they can be involved in economic growth. In our quantitative research we studied what the connection between financial status, identity, financial consciousness and health consciousness are among women. Our results confirms that the income status, degree of consciousness and "identity" mostly influence the existence of a healthy diet. Furthermore, a strong correlation is found between health consciousness, financial attitude and a sense of overall well-being.

Keywords: consumption, health, household, management JEL classification: E21, H31, H51

\section{Introduction}

The issue of healthy consumption based on knowledge is a very timely topic nowadays. These days one of the megatrends is health consciousness and the extension of the health market. For consumers the role of health has been appreciated and we spend more and more to stay healthy. (Töröcsik, 2011) The individual has the greatest role in keeping good health. Who really takes care and pays attention to prevent illnesses and diseases has lower chances to be ill, or if so, and they are quick to realise the symptoms of illnesses, and they recover sooner. Prevention has an important role in the individuals 'keeping their physical and mental health for a longer time and remaining active, and accordingly, they can be involved in economic growth (Róna et al, 2010). Healthy lifestyles and ways of living are gaining more importance in our lives. The European Population Health Survey identifies four different types of behaviour, which include the passive health conscious, those who lack health consciousness, and people who are less health conscious and finally the health conscious. Health conscious are the people who make use of the opportunities provided by the healthcare system; for them it is important to preserve their life and have a balanced diet. They do not consume any alcohol and do no refuse alternative methods of cure and regularly take food supplements. Millward Brown Healthcare and TGI (Target Group Index) conducted 
joint research in 2010 about health consciousness on the population aged between 18 and 69. According to the main findings the preventive approach of the Hungarian people is not fully fledged yet as we still deal with our health in case of 'emergency'. Approximately $50 \%$ of the adult population feel there is nothing more necessary to do to preserve their health. As far as the other part of the population is concerned they avoid meeting doctors $852 \%$ ) and taking pills (38\%), as well. Half of the respondents stated to have a positive attitude when it comes to health; they say they themselves can shape their health status by being totally aware. The real preventive attitude and practice are still in their infancy or they do not exist at all and just appear in the everyday life of a small segment of the population.

Based on the idea motivation and behavioural intention are the prerequisites to trigger a form of behaviour and, in addition, four more factors are also necessary. The individual must possess proper knowledge and abilities; make a difference between the forms of behaviour and it is also essential to have suitable environmental conditions so as not to hinder the person from acting regularly. Our research examines the following statements on the topics of 'attitude', more precisely, 'attitude toward behaviour', 'behavioural intention', the descriptive part of 'perceived norm' and 'dispositive norm' as well as the 'importance of norm'. Basically, similar parts and ratios are included in a dietary recommendation made by a research group from Harvard University in which a pyramid is used for illustration. This food guide pyramid is used in our research, as well, to serve as a sample of healthy nutrients and proportions.

Significance of financial attitude. Nowadays conscious consumption is gaining more and more ground in several areas of life of which health consciousness and financial consciousness are dealt with. In our opinion the conscious and successful managing of finances and health conscious attitude are in tight relation as both of them reflect rational well-being based on discretion. To have a healthy diet every day we have to possess a decent salary so a deep insight into finance is a must. At this stage the most important, and for us, the most relevant findings of financial culture and financial attitude are disclosed. There is a tight correlation between attitude to money and certain demographic factors. One of the most frequently used scales of financial attitude is "MAS" (Money Attitude Scale developed by Yamauchi and Templer (1982). The authors primarily relied on Freudian and NeoFreudian theories, which supposed three basic parts in the nature of financial attitude. They are Security, Retention and Power prestige. By means of factor analysis four of the five categories were defined. The fifth factor was added later by Roberts and Sepulveda in their research (1999): "Power - Prestige"; "Retention-Time"; "Mistrust"; "Anxiety"; "Quality". The scale of the authors was used by several researches in its original or modified form (Andersen, Camp, Kiss, Wakita, and Weyeneth, 1993). They also created a so-called 'action-conscious/obsessed' factor . Our research examined the categories of 'retention-time', 'anxiety-worry' and 'cost consciousness-obsession'. Several statements were drafted to point out the correlation between income and attitude to money. There is some research that point out that individuals with higher salary are more anxious about money matters. According to Furnham (1984) individuals with low income are more characterised by anxiety. Tang and Gilbert (1995) in their paper concluded than those who live on less money are more carefully in managing it. Another interesting result is that for those with higher salary money means comfort and safety (Wernimont - Fitzpatrick, 1972).

Correlations between identity and health. Doyal and Gough (1991) set the objective of freedom of all types of oppression and rendition and its conditions are sought from the point of view of satisfying needs. They regard health and autonomy 
as basic needs. They suppose that physical and mental health is the most basic human requirement, whose satisfaction is individual interest. The other group of basic needs can be linked to identity or autonomy. They define it as the basic need for creative knowledge, the skill of drafting objectives and strategies necessary for reaching the targets theoretically. (Doyal-Gough, 1991) Identity is a multidisciplinary notion prevalent not only in psychology, sociology but also in economics as a moderating factor of economic processes. There are several types of identity such as ethnic, national, linguistic, religious, gender, class identity etc. Our paper primarily deals with social identity as we think this has made an impact on health and conscious consumption the most. Social identity can be lined to Erving Goffman which can be defined as follows. The expected behaviour is not only influenced by social roles but also the selection of personal values such as honesty, beauty etc. The most important issue is what identities and structure of identities the person concerned regards valid for themselves. From the research carried out by the University of Antwerp and financed by the European Commission - in which the reference budget was analysed in Europe - several different social roles were stated of which the role of women is listed below. The categories are as follows: mother, student, manager of their own enterprise/company, housewife, member of an association /organisation (e.g. business, sport, in relation to gender identity etc.), independent woman, wife, citizen, friend. These social positions were created in line with official social requirements and the international directives of EU member states. When creating categories social expectations and indispensable dire human needs were also considered. (Storms et al., 2014)

Our research is primarily aimed at finding what factors determine health consciousness and a healthy diet. Our central hypothesis was that material situation, the level of consciousness and identity can have a decisive say in the question of who is willing to lead a healthy diet. We also thought correlations exist between health consciousness and financial attitude as well as between health consciousness and general well-being, respectively.

\section{Methodology}

Based on the correlations and our experience drafted above the following hypotheses were formulated. $\mathrm{Hl}$ : Behavioural intention and normative beliefs are positively correlated with healthy diet. H2: The eating habits of those with higher income are mostly defined by their knowledge/information. H3a: Those whose eating habits are characterised by scarcity are strong in the factors of anxiety/worry and money consciousness/obsession. H3b: Women working in the public sector are less characterised by consuming healthy food than those in the private sector. (The primary reason for this is the much lower average salary). H4: The eating habits of those who identify themselves mostly through female roles are primarily defined by knowledge/information.

Participation in the research was voluntary. Online questionnaires were used that were filled in in March 2017. They were filled in by 195 women. The questionnaire consisted of several question types such as simple choice, matrix, ranking order and short answers to a picture. The topics dealt with by the questionnaire include the following.

I. The life and soul of healthy diet-checking the integrated behavioural model;

II. Correlations between income and health consciousness;

III. Correlations between financial consciousness and health consciousness;

IV. Correlations between identity and health consciousness. 


\section{Results}

I. The examined population was divided into two parts: those who mostly think they consume 'a healthy amount' of the food recommended in the food guide pyramid and those who do not. (The first group consisted of the respondents who had 5 or more 'yes' answers of the 7 item, i.e. $40 \%$ while the remaining $60 \%$ made up the second group.) We were interested to know what demographic and other features characterise the two groups and whether there were significant differences. That is why we examined the differences in terms of age, occupation, income and identity and also the factors that determine the eating habits of these two groups.

Regarding age there was no significant difference. As it can be seen the middle aged (between 26 and 50) would rather consume healthy amounts of different food as they admit. No correlations were found between the other variables. It can be seen, however, that the integrated behavioural model is justified, i.e. motivation and behavioural intention are inevitable for the latter one to come true. The following items of the model were used:

Table 2

Used Items of IBM Model

\begin{tabular}{lllll}
\hline $\begin{array}{l}\text { Attitude/experien } \\
\text { tial attitude }\end{array}$ & $\begin{array}{l}\text { Behavioural } \\
\text { intention }\end{array}$ & $\begin{array}{l}\text { Perceived } \\
\text { norms/ } \\
\text { dispositive } \\
\text { norm }\end{array}$ & $\begin{array}{l}\text { Perceived } \\
\text { norms/descriptiv } \\
\text { e norm }\end{array}$ & $\begin{array}{l}\text { Importance } \\
\text { of norms }\end{array}$ \\
\hline $\begin{array}{l}\text { I find a health } \\
\text { way of life } \\
\text { enjoyable. }\end{array}$ & $\begin{array}{l}\text { I wish to live } \\
\text { more } \\
\text { healthily. }\end{array}$ & $\begin{array}{l}\text { Formy } \\
\text { acquaintances } \\
\text { healthy is a } \\
\text { value/asset. }\end{array}$ & $\begin{array}{l}\text { My acquaintances } \\
\text { do a lot for their } \\
\text { health. }\end{array}$ & $\begin{array}{l}\text { I do not } \\
\text { the others } \\
\text { think of me. }\end{array}$ \\
$\begin{array}{l}\text { To lead a healthy } \\
\text { way of life is a } \\
\text { pleasant thing. }\end{array}$ & $\begin{array}{l}\text { I strive to } \\
\text { lead a } \\
\text { healthier } \\
\text { way of life. }\end{array}$ & & $\begin{array}{l}\text { Most people do } \\
\text { alot for their } \\
\text { health. }\end{array}$ & \\
\hline
\end{tabular}

Source: Author's Table

Those who typically agreed with the statement 'I find a health way of life enjoyable' (Sig.0.000), 'to lead a healthy way of life is a pleasant thing' (Sig.0.000), 'for my acquaintances healthy is a value/asset (Sig.0.027) and 'I strive to lead a healthier way of life' (Sig.0.000) consume significantly healthier amounts of the items of the Harvard pyramid according to the results of the variance analysis.

We were also curious to know how critical the persons who admitted to eat healthily or in general, more healthily are to the results of the food guide pyramid of the Harvard research. We expected that those who are more conscious would rather reassess the general food guides. However, no statistical significant correlation was found. This can be due to the fact that the respondents are likely to paint a better picture in terms of a healthy diet. At the same time, to be well-informed and knowledgeable (that is a prerequisite of healthy diet) would not prevail in a more concrete knowledge test. It would be worth examining what knowledge the respondents have. (Vitamins, oily seeds, beans and tofu were indicated to be lacking by many as a response to the question of whether they think they consume 
healthy amounts of different food. For the entire sample seeds are $42 \%$, vitamins $289 \%$, respectively.)

We also examined whether the judgment of their own diet correlates with the intention of making changes to preserve their health. Seventy-one percent of the respondents stated they mostly eat healthily or in general, they eat healthily. Those who confessed they 'pay attention to eat more healthily' in $66 \%$ said they had already thought of changing their eating habits. Those who responded to eat healthily in general, in $87 \%$ would like to change. A similar proportion of those who mostly do not or do not at all eat healthily, i.e. $84 \%$ would like to change their eating habits, as well. The differences are significant (Sig.0.007). Sixtysix percent also refers to the fact that we encountered a classical methodological problem when recording the questionnaire, i.e. the respondents wanted to meet the requirements of the interviewer, so that is why he painted a better picture when asked „Do you think you have a healthy diet?" When asked about their behavioural intentions („Have you ever thought of changing your eating habits?...") this kind of attitude is not present and they are willing to admit the intention to change, i.e. they cannot have such a healthy diet as stated previously. The question of "Have you ever thought of changing...." functions as a checking question in this case.

Based on the research it can clearly be stated that $79.3 \%$ of the respondents would change their eating habits to lead a healthier way of life. This correlates with the previous research findings. We were also curious to find out what can lie behind the intention to change. We supposed that if a person would like to change their eating habits, the reason for this could be a serious health problem. (155 declared not to have any serious health problem and only $20.1 \%$, i.e. 39 respondents admitted to be suffering from an illness.) We examined the cross table of the two questions by means of Chi2 test. To the researchers' great surprise, the same proportion was gained. Of those who would change $20 \%$ have a serious illness or problem and of those who do not the proportion is the same, i.e. $20 \%$. It can be due to the fact that no correlation was found between illnesses and eating habits.

II. What determines eating habits primarily? Regarding the factors that determined eating habits knowledge (being well-informed) was the most decisive $136 \%$ of the sample responded this way). Those whose eating habits are predominantly determined by their financial situation made up $17 \%$ of the sample. Only $10 \%$ said to make habit-based decisions on eating and only $5 \%$ stressed the importance of brand loyalty.

We separated the women who replied that knowledge and information are in general or most decisive in their eating habits from those for whom knowledge and information play a minor or slight role. In line with this, we tried to identify what characteristics these two groups had. We supposed that the knowledge of women who had higher income was greater in this area, too. They can adapt their eating habits to what is good for them and their decision is not influenced by lack of money. According to our findings $78 \%$ of those with a salary above $250.000 \mathrm{Ft}$ stated that it is their knowledge or information that that mostly or in general influence their eating habits (Sig.0.05). For those with more than 350.000Ft this ratio is even higher, $83 \%$. It can be seen that as income increases, information and knowledge in eating habits are becoming more decisive. Regarding age no significant correlations were found. Unfortunately, the statement according to which increasing income would result in healthier eating habits resulting in a better health status is not justified by our research results. It could partly be due to the fact that general health status was not asked; only a question was directed at whether the respondents had a serious healthrelated problem. So carrying out statistical analysis was impossible in this direction. In 
the case of serious health-related problems it can be seen that they are not linked to demographically well-described groups. However, interesting correlations were found with regard to the typical IBM and financial attitudes of this group. The following part presents only the significant correlations.

In the case of IBM the first item ('I find a health way of life enjoyable') showed a significance of 0.000 , the third item ('to lead a healthy way of life is a pleasant thing') 0.015, the seventh ('for my acquaintances healthy is a value/asset) 0.01 and the eighth ('I strive to lead a healthier way of life') 0.000. It is obvious that regarding these items the more knowledgeable agreed with these statements to a greater extent. An interesting correlation is that those who form knowledge-based eating habits enjoy them. So the psychological correlation according to which the more energy we put into something, the more we appreciate it and find reasons why we enjoy it.

No significant correlations were detected between the statements on financial attitude and knowledgeability in the case of those who form habits on the basis of their knowledge and information, which is a bit surprising as we expected that those with higher financial consciousness also show high level of awareness and consciousness in other areas of life. This type of generation is not justified by our research. At the same time, however, when examining the group whose eating habits are mostly or in general determined by their financial status, the correlations were in line with our expectations. Sixty-four percent of those with lower salaries (below 150.000Ft) state that their financial status mostly or in general determine their eating habits while the ratio is $19 \%$ in the case of those who earn more labove $250.000 \mathrm{Ft})$, so it is not surprising that they can lead a less healthy way of life. Those significant in the item 'I strive to lead a healthier way of life' (Sig. 0.006) show higher values. Also higher values can be seen in the dimensions of 'anxiety-worry' and 'cost consciousness-obsession'. Extremely strong significance was detected in the following items: "I am a bargain hunter." (Sig. 0.000); ", I am concerned if it comes to money" (Sig. 0.000); "I often automatically think to myself I cannot afford even if it is not true" (Sig. 0.021); "I am angry if I miss a sale" (Sig. 0.002); ". After having bought something I am worried that I could have bought it cheaper" (Sig. 0.003). It is obvious that those whose eating habits are determined by scarcity are stronger in the dimensions of 'anxiety-worry' and 'cost consciousness-obsession'.

Regarding source of income the respondents of the public and private sector were separated. Sixty-four percent of those working in the public sector and $74 \%$ of those from the private sector said that it is knowledge and information that mostly determined their eating habits. However, no significant correlation could be detected. Though when examining the impacts of the financial situation on the eating habits, $59 \%$ of the respondents from the public sector and $42 \%$ of the private sector regarded it as a decisive aspect (Sig, 0.042.).

With regard to the hypothesis "Women working in the public sector are characterised by eating healthier food to a smaller extent than their counterparts in the private sector." based on the results of the Chi-square trial significant correlation could be found between the variables so this hypothesis is justified. $60.2 \%$ of those who work in the private sector think they eat healthily while only $39.8 \%$ from the public sector think they have a healthy diet. To conclude, it can be stated that women working in the private sector eat healthier food. There is a correlation, as well, according to which those in the private sector earn more than those in the public sector. Forty four percent of the former ones in the sample earn more than $250.000 \mathrm{Ft}$ while it is only $29 \%$ in the public sector. We also examined how the source of income affects eating habits. Regarding the impacts of the financial situation significant differences were found. Fifty nine percent of the respondents in the public 
sector stated that in general or mostly it is their financial situation that determines their eating habits while it is only $47 \%$ in the private sector. The correlation according to which the more you earn, the more knowledge-based and conscious decisions you make in your everyday life, and, as a result, your diet is healthier, has been justified.

One of the bases of our research was that the individual's identity can significantly influence how health conscious they are and accordingly, how their eating habits are formed. However, the question directed at this point in our questionnaire proved to be too complex so only few statistically assessable responses were received. As a result, no significant correlation could be detected in connection with the hypothesis $\mathrm{H} 4$, i.e. the identified identity categories (mother manager, wife, student etc.) did not show significant differences in health consciousness.

\section{Conclusion}

Our research has justified the following.

1. Experiential attitude, behavioural intention and norms perceived in the environment are in close connection with the prevalence of a healthy diet.

2. We expected that the knowledge and information of women with higher income would primarily determine their eating habits. Our research has proved that with the increase of income, information and knowledge are gaining more and more importance. Accordingly, income plays a decisive role in the fact whether one can have a healthy diet as it is much more expensive and time consuming than the routine, not thoroughly planned one.

3. Those whose eating habits are primarily determined by their financial situation (as, at least, they have put it) instead of the information/knowledge or brand loyalty belong to the category of those with lower than average income. This group is more worried in financial matters and they are characterised by budget consciousness and bargain hunting, as well.

A new, complex approach of healthy diets of the contemporary research in Hungary was applied in our paper. The traditional research on consumer behaviour examined the buyers' behaviour. By making use of the results in international literature we have strengthened the psychological approach. We suppose it is going to be very useful for food producers and consumers alike, in addition to researchers. The limitations of our research is the small and not representative so there would be worthy to repeat it in a bigger sample.

\section{References}

1. Andersen, J., Camp, P., Kiss, E., Wakita, S., Weyeneth, J. (1993), "The money attitude scale: what college students think about green stuff", The Proceedings of the American council on Consumer Interests, Vol. 39, pp. 377-384.

2. Doyal, L. Gough I. (1991), A Theory of Human Need, Houndmills, Macmillan.

3. Furnham, A. (1984), "Many sides to the coins. The psychology of money usage", Personality and Individual Differences, Vol. 5 No. 5, pp. 501-509.

4. Róna, P., Rácz J., Rózsa A., Szepesi A., Törőcsik M., Kató G., Repa I., (2010), "A paradigmaváltás alapjai", Egészségügyi gazdasági szemle, Vol. 1, pp. 45-48.

5. Storms B., Goedemé T., Van den Bosch K., Penne T., Schuerman N., Stockman S. (2014), "Review of current state of play on reference budget practices at national, regional, and local level, Pilot project for the development of a common methodology on reference budgets in Europe", Contract no. VC/2013/0554, Brussels: European Commission. 
6. Tang, T. L. P., Gilbert, P. R. (1995), "Attitudes toward money as related to intrinsic and extrinsic job satisfaction, stress and work-related attitudes", Personality and Individual Differences, Vol. 19 No. 3, pp 327-332.

7. Yamauchi, K. T., Templer, D. L. (1982), "The development of money attitude scale", Journal of Personality Assessment, Vol. 46 No. 5, pp. 522-528.

8. Wernimount, P., Fitzpatrick, S. (1972), "The meaning of money", Journal of Applied Psychology, Vol. 56 No 1, pp. 218-226.

\section{About the authors}

Nikolett Mihaly, Ph.D. is an Assistant Professor of Economic Psychology at the Department of Marketing, Faculty of Economics and Business, at Szent Isvan University of Gödöllö. Her current research areas are financial consciousness and higher education institution management. She is the (co)author of number of articles in international and national journals. She is actively engaged in number of scientific projects and collaborates in several applied projects in the field of financial education, marketing and management. Author can be contacted at mihaly.nikolett@gtk.szie.hu.

Nándor Komáromi, Ph.D. in Economics is Associate Professor at the Szent István University in Hungary, Since 1993 he teaches marketing and management subjects several universities in Hungary. He attended by about 120 research projects (scientific and applied topics; national and international). His research interests are application of statistical methods and quantitative methods; model development; the practical application of marketing research. Author can be contacted at komaromi.nandor@gtk.szie.hu.

József Lehota, DSc in Economics full-time marketing professor in Szent István University and part-time marketing professor in Debrecen University. From 2014, he is Head of Doctoral School of Management and Business Administration in SIU. He is author, and co-author of number of articles in international and national journals and attended severeal national and international research projects. His research interests are food consumer behaviour and buying behaviour in organisational markets. Author can be contacted at lehota.jozsef@gtk.szie.hu. 